BMJ Open

Diabetes

Research

\& Care

\title{
Occupational distribution of metabolic syndrome prevalence and incidence differs by sex and is not explained by age and health behavior: results from 75000 Dutch workers from 40 occupational groups
}

\author{
Sander K R van Zon (D) , ${ }^{1}$ Benjamin C Amick III, ${ }^{2}$ Trynke de Jong, ${ }^{3}$ \\ Sandra Brouwer, ${ }^{1}$ Ute Bültmann ${ }^{1}$
}

To cite: van Zon SKR, Amick III BC, de Jong T, et al. Occupational distribution of metabolic syndrome prevalence and incidence differs by sex and is not explained by age and health behavior: results from 75000 Dutch workers from 40 occupational groups. BMJ Open Diab Res Care 2020;8:e001436. doi:10.1136/ bmjdrc-2020-001436

- Additional material is published online only. To view please visit the journal online (http://dx.doi.org/10.1136/ bmjdrc-2020-001436).

Received 3 April 2020 Revised 16 May 2020 Accepted 26 May 2020
Check for updates

\section{(c) Author(s) (or their} employer(s)) 2020. Re-use permitted under CC BY. Published by BMJ.

For numbered affiliations see end of article.

Correspondence to Dr Sander K R van Zon; s.k.r.van.zon@umcg.nl

\section{ABSTRACT}

Introduction This study examines the association between 40 occupational groups and prevalence and incidence of metabolic syndrome (MetS), separately for male and female workers, and whether age and health behaviors can explain the association.

Research design and methods Data from 74857 Lifelines Cohort and Biobank Study participants were used to regress occupational group membership, coded by Statistics Netherlands, on the prevalence and incidence of MetS using logistic and Cox regression analyses. MetS diagnosis was based on physical examinations, blood analysis, and recorded medication use. Information on age, smoking status, physical activity, diet and alcohol consumption was acquired using questionnaires. Results Baseline MetS prevalence was $17.5 \%$ for males and $10.6 \%$ for females. During a median 3.8 years of follow-up, MetS incidence was $7.8 \%$ for males and $13.2 \%$ for females. One occupational group was associated with an increased MetS risk in both sexes. Six additional occupational groups had an increased risk for MetS among men, four among women. Highest risks were found for male 'stationary plant and machine operators' (HR: 1.94; $95 \% \mathrm{Cl} 1.26$ to 3.00 ) and female 'food preparation assistants' (HR: $1.80 ; 95 \% \mathrm{Cl} 1.01$ to 3.22 ).

Conclusions Findings suggest that occupational group matters for men and women in MetS development, and that differences in MetS prevalence across occupations are not merely a reflection of selection of metabolically unhealthy workers into specific occupations. The striking sex differences in the occupational distribution of MetS indicate that preventive measures should, with some exceptions, target men and women separately.

\section{INTRODUCTION}

Metabolic syndrome (MetS), a cluster of preclinical conditions (ie, central obesity, insulin resistance, hypertension, raised triglycerides and lowered high-density lipoprotein (HDL) cholesterol), ${ }^{1}$ doubles the risk

\section{Significance of this study}

What is already known about this subject?

- Occupational group membership is associated with metabolic syndrome prevalence.

- Age and health behaviors are associated with metabolic syndrome.

What are the new findings?

- Occupational group membership is associated with metabolic syndrome incidence.

- Age and health behaviors do not account for the increased incidence in all occupational groups.

- There are striking sex differences in the occupational distribution of metabolic syndrome incidence.

How might these results change the focus of research or clinical practice?

- The striking sex differences in the occupational distribution of metabolic syndrome indicate that preventive measures should, with some exceptions, target male and female workers separately.

- Researcher should further investigate how the workplace can be optimized as a setting for health promotion and prevention of cardiometabolic conditions like metabolic syndrome.

of cardiovascular outcomes and more than triples the risk for type 2 diabetes mellitus (T2DM). ${ }^{2} 3$ In addition, the average annual healthcare costs are 1.6 times higher for people with MetS than for people without MetS. ${ }^{4}$ The global prevalence of MetS is currently about $25 \%$, which means that over a billion people are affected. ${ }^{5}$ The prevalence of MetS increases with age and prevalence estimates in Europe range from $4 \%$ among 20-29year-olds to almost $30 \%$ among 60-69 year-olds. ${ }^{6}$ 
The proportion of working-age individuals with MetS underscores the need to understand the role of work in contributing to the population distribution of MetS. ${ }^{6} \mathrm{An}$ important step in examining the role of work in MetS is to surveil the occupational distribution of MetS. To date, studies have shown that occupational groups that require lower skill levels, like 'machine installers, operators, and assemblers', 78 'construction workers', ${ }^{9}$ and 'food preparation occupations' ${ }^{10}$ have the highest prevalence of MetS. Studies on components of MetS found similar occupations like 'motor vehicle operators', 'transportation workers' but also 'protective services' to be associated with high rates of obesity ${ }^{11-14}$ and hypertension. ${ }^{1516}$

Yet, current evidence is limited in at least two ways. First, studies on MetS are cross-sectional and therefore do not clarify whether occupational group membership contributes to the development of MetS or differences are merely a reflection of selection of metabolically unhealthy workers into specific occupational groups. ${ }^{7-10}$ Second, studies did not adjust the relationship between occupational groups and MetS for smoking, physical activity, diet and alcohol consumption ${ }^{79}$-health behaviors known to predict MetS, ${ }^{17}$ or did so with limited information on occupational group membership (ie, adjusted analyses with only five or 13 occupational groups). ${ }^{8} 10$

Furthermore, the occupational distribution of MetS is likely to differ between men and women for several reasons. Certainly, men and women have different work experiences and therefore any assessment of the role of work must examine population-based sex differences by occupation. In addition, the etiology of MetS and its components, and the prevalence of MetS, differ between men and women. ${ }^{18-21}$ Most noticeably, sex hormonal influences differ in men and women and could explain sex differences in the etiology and prevalence of MetS. ${ }^{1820}$ Sex-stratified analyses are therefore needed when investigating MetS, especially in the context of work. ${ }^{21}$ Studies assessing the sex-specific occupational distribution of MetS find remarkable differences between men and women. ${ }^{79}$ Most notably, MetS prevalence is thrice as high among males in high-end jobs like 'general managers and government administrators' than among their female counterparts. ${ }^{7}$

Against this background, three research questions about MetS prevalence and incidence rates using a sexspecific approach are addressed. First, are occupational groups associated with MetS? Second, are associations of occupational group and MetS due to the age distributions across occupational groups? Third, are the associations of occupational group and MetS influenced by smoking, physical activity, diet and alcohol consumption-health behaviors known to predict MetS?

\section{RESEARCH DESIGN AND METHODS}

\section{Study design and sample}

The study was conducted using data from the longitudinal Lifelines Cohort Study. ${ }^{22}$ Between 2007 and 2013, a total of 167729 persons living in the northern part of the Netherlands were recruited through general practitioners, family members and self-registry. At baseline, participants visited one of the Lifelines research centers for a physical examination and collection of biological samples. Participants further completed extensive questionnaires. In total, 152728 adult participants were included at baseline. Participants received follow-up questionnaires after approximately 1.5, 3 and 5 years. After 5 years, participants also revisited one of the Lifelines research centers for a physical examination and collection of biological samples. For the current study, we selected participants of working age (ie, 18-64 years old), who were part of the working population according to the Dutch and international definition (ie, working at least 1 hour per week), ${ }^{23}$ and who completed the first and second physical examinations. With these restrictions, 12689 of 152728 participants were excluded due to age ineligibility, 22742 participants were excluded because they were not working, and 40563 participants were excluded because they had no follow-up measurement (ie, did not yet complete the measurement or lost to follow-up).

\section{Measures and procedures \\ Occupational group membership}

Occupational group membership was assessed at baseline by asking participants about their occupation and the main tasks related to their occupation. Statistics Netherlands coded all occupations automatically according to the International Standard Classification of Occupations (ISCO) $08 .{ }^{24}$ We performed a quality control by selecting a $1 \%$ subsample of the complete baseline data set $(n=1432)$. Statistics Netherlands provided a certainty score (range 0-100), indicating how well occupations could be coded based on the information participants provided. We examined possible misclassification regardless of the certainty score and for different cut-off values (ie, certainty scores $\geq 50, \geq 60, \geq 70$, and $\geq 80$ ).

Forty of the 43 submajor occupational groups (ie, two-digit level) were included in our analyses. ${ }^{25}$ Three submajor occupational groups belonging to the major occupational group 'armed forces' were excluded because the number of participants in this major occupational group was very small $(n=129)$. We also explored a more refined grouping of occupational groups (threedigit codes) but the sample size was too small in many occupational groups. We had no ISCO classification for 1748 participants (ie, missing data) so they were excluded from the analytical study sample. The selection of the analytical study sample is shown in online supplementary figure 1 .

The quality control showed that at least $81.2 \%$ of the occupational classifications were correct at the submajor group level when the certainty level was not taken into account (online supplementary table 1). Misclassification decreased with an increasing certainty score, with 92.7\% agreement on the submajor group level when the 
certainty score was $\geq 60$. However, $44.7 \%$ of participants in the total sample had a score $<60$. The proportion of participants with a certainty score $<60$ was largest among managers $(68.6 \%)$ (online supplementary table 2 ).

\section{Metabolic syndrome}

MetS was defined according to the joint interim criteria. ${ }^{1}$ The diagnosis MetS was established if at least three of the following five components were present: (1) central obesity (waist circumference (WC) $\geq 102 \mathrm{~cm}$ in men, WC $\geq 88$ in women), (2) raised triglycerides $(\geq 1.7 \mathrm{mmol} / \mathrm{L})$ or treatment for this lipid abnormality, (3) reduced HDL cholesterol $(<1.0 \mathrm{mmol} / \mathrm{L}$ in men, $<1.3 \mathrm{mmol} / \mathrm{L}$ in women) or treatment for this lipid abnormality, (4) elevated blood pressure (systolic blood pressure (SBP) $\geq 130 \mathrm{~mm} \mathrm{Hg}$ and/or diastolic blood pressure (DBP) $\geq 85 \mathrm{~mm} \mathrm{Hg}$ ) or treatment of previously diagnosed hypertension, (5) raised fasting plasma glucose (FPG) $(\geq 5.6 \mathrm{mmol} / \mathrm{L})$ or previously diagnosed T2DM. WC was measured in an upright position and in the middle between the front end of the lower ribs and the iliac crest. Triglycerides and HDL cholesterol were determined based on fasting blood samples. Treatment for lipid abnormality, that is, cholesterol-lowering medication (ie, Anatomical Therapeutic Chemical (ATC) codes C10A, C10B), was recorded at baseline only. ${ }^{26}$ Mean SBP and DBP were measured using an automatic blood pressure monitor. ${ }^{22}$ Antihypertensive medication (ie, ATC codes C02, C03, $\mathrm{C} 07, \mathrm{C} 08, \mathrm{C} 09$ ) was recorded only at baseline. ${ }^{26} \mathrm{FPG}$ was determined based on fasting blood samples. Previously diagnosed T2DM was based on medication use (ie, ATC codes A10A, A10B) only at baseline. ${ }^{26}$ Physical measurements and blood samples were taken by trained research staff using standardized protocols and calibrated measuring equipment. ${ }^{22}$

\section{Sociodemographic factors and health behavior}

Baseline sociodemographic factors and health behaviors included age, gender, educational level, smoking status, alcohol consumption, physical activity, and dietary habits and were, except for dietary habits, coded in accordance with previous studies using Lifelines data. ${ }^{27}$ Dietary habits were coded based on the Dutch guideline for healthy nutrition. ${ }^{28}$ Educational level was categorized into low, medium and high. Smoking status was categorized as being a current smoker, ex-smoker, or never smoker. Alcohol consumption was categorized into drinking 0 days/week, drinking 0-1 days/week, drinking $>1$ to 3 days/week and drinking $>3$ days/week. Physical activity was based on the number of days per week participants were active for at least half an hour (eg, bicycle, exercise) and was categorized into being inactive ( $0-2$ days per week), moderately active (3-4 days per week), or active ( $\geq 5$ day per week). Diet was based on fruit and vegetable consumption. Participants eating both fruits and vegetables $\geq 4$ days per week were categorized as having a healthy diet, participants eating fruits $\geq 4$ days per week but vegetables $<4$ days per week, or vice versa, were categorized as having a moderately healthy diet, and participants eating both fruits and vegetables $<4$ days per week were categorized as having an unhealthy diet.

\section{Statistical analyses}

First, the distribution of baseline sociodemographic and health behavior factors was examined for the total population and separately for men and women. Differences between participants excluded for missing follow-up data $(n=40563)$ and those included were examined to assess possible bias. Second, the association between baseline MetS prevalence and submajor occupational groups was estimated using sex-specific logistic regression analyses. Third, the risk of 5-year incidence of MetS by submajor occupational group was estimated using sex-specific Cox regression analyses. Both cross-sectional and longitudinal analyses were, after crude analyses (model 1), adjusted for age (model 2), and smoking, physical activity, diet, and alcohol consumption (model 3) to understand the unique contribution of occupational group in determining the MetS population distribution. Educational level is not adjusted for because it conceptually overlaps with occupational group membership. These two factors were moderately correlated in our data set (Spearman's correlation: 0.56). 'Science and engineering professionals' were the reference category because they have a high occupational skill level and the certainty score for the occupational coding of 'professionals' was considerably higher than for 'managers', who also have a high occupational skill level (online supplementary table 2).

\section{RESULTS}

\section{Baseline characteristics}

In total, 31969 men and 42888 women were included in the study (table 1 ). The mean age was 43.0 years (SD: $10.0)$ for men and 42.1 years (10.2) for women. Baseline MetS prevalence was $17.5 \%$ (5590/31 969) for men and 10.6\% (4540/42 888) for women. The baseline prevalence of central obesity and reduced HDL cholesterol were higher among women while raised triglycerides, elevated blood pressure and raised FPG were more common among men. Baseline characteristics of participants with and without follow-up data differed for some variables, but differences were generally small (online supplementary table 3). Baseline study participants without follow-up data were younger, had poorer health behavior, and had higher rates of reduced HDL and increased glucose levels, but lower rates of raised blood pressure and MetS. The median follow time was 3.8 years (IQR: 3.1-4.7 for men; 3.1-4.6 for women) and $7.8 \%(2068 / 26379)$ of men and $13.2 \%$ (5044/38 348) of women developed MetS, respectively.

\section{MetS prevalence by occupational group}

MetS prevalence across occupational groups was generally higher for men than women (online supplementary figure 2). Among men, 'drivers and mobile plant operators' $(25.7 \%)$ and 'hospitality, retail and other service 
Table 1 Baseline characteristics for the total study sample and for men and women

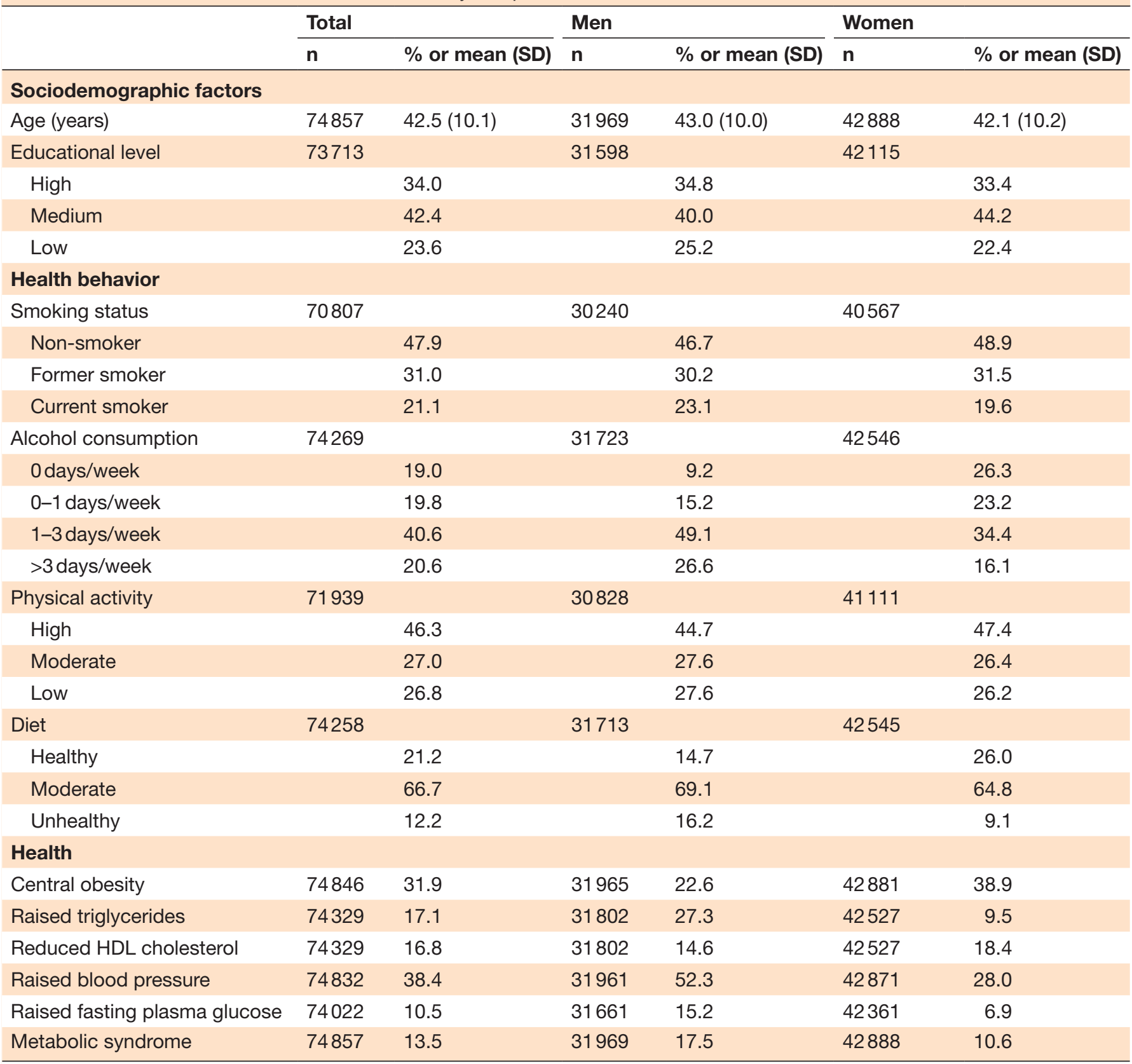

HDL, high-density lipoprotein.

managers' (25.2\%) had the highest rates of MetS while the prevalence among women was highest for 'assemblers' $(21.7 \%)$ and 'drivers and mobile plant operators' $(20.0 \%)$. Online supplementary table 4 show the stepwise-adjusted associations between the occupational groups and MetS for men. In the unadjusted model (model 1), 14 occupational groups were associated with an increased odds for MetS, which was reduced to 11 after adjustment for age (model 2), and 6 after adjustment for health behavior (model 3). For men, 'hospitality, retail and other service managers' (OR: 1.65; 95\% CI 1.03 to 2.65) and 'drivers and mobile plant operators' (OR: 1.57 ; $95 \%$ CI 1.28 to 1.93 ) had the highest ORs for MetS. Online supplementary table 5 shows the stepwise-adjusted associations for women. In the unadjusted model, 23 occupational groups were associated with an increased odds for MetS. The number with increased odds decreased to 18 after adjustment for age and 12 after adjustment for health behavior. 'Stationary plant and machine operators' (OR: 3.44; 95\% CI 1.57 to 4.54) and 'assemblers' (OR: 3.43; 95\% CI 1.26 to 9.33) had the highest odds for MetS. Only three occupational groups were associated with an increased odds for MetS in both men and women (ie, 'customer services clerks', 'stationary plant and machine operators', and 'drivers and mobile plant operators'). All other associations were sex specific. 


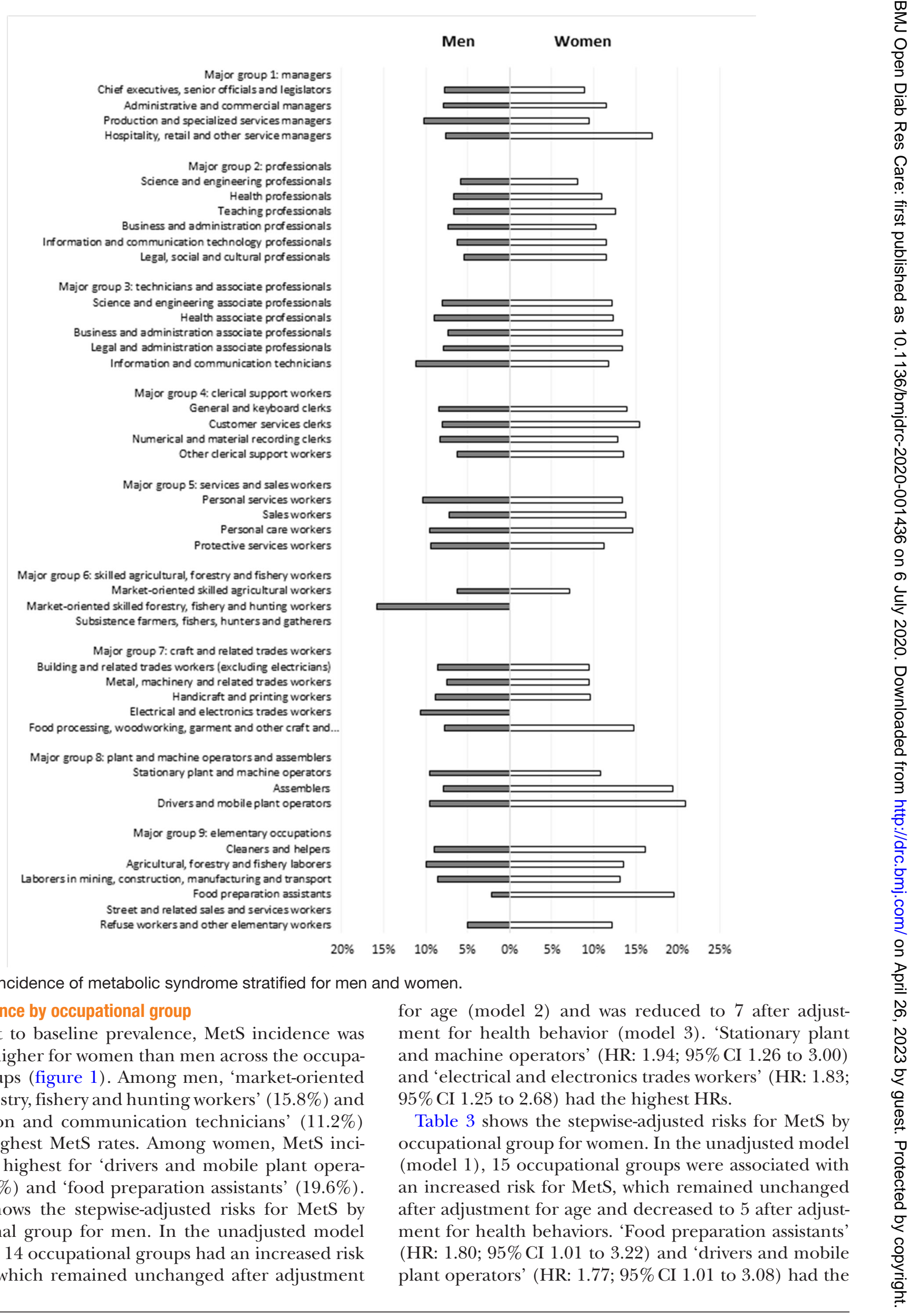


Table 2 The incidence of metabolic syndrome among men, and its association with submajor occupational groups

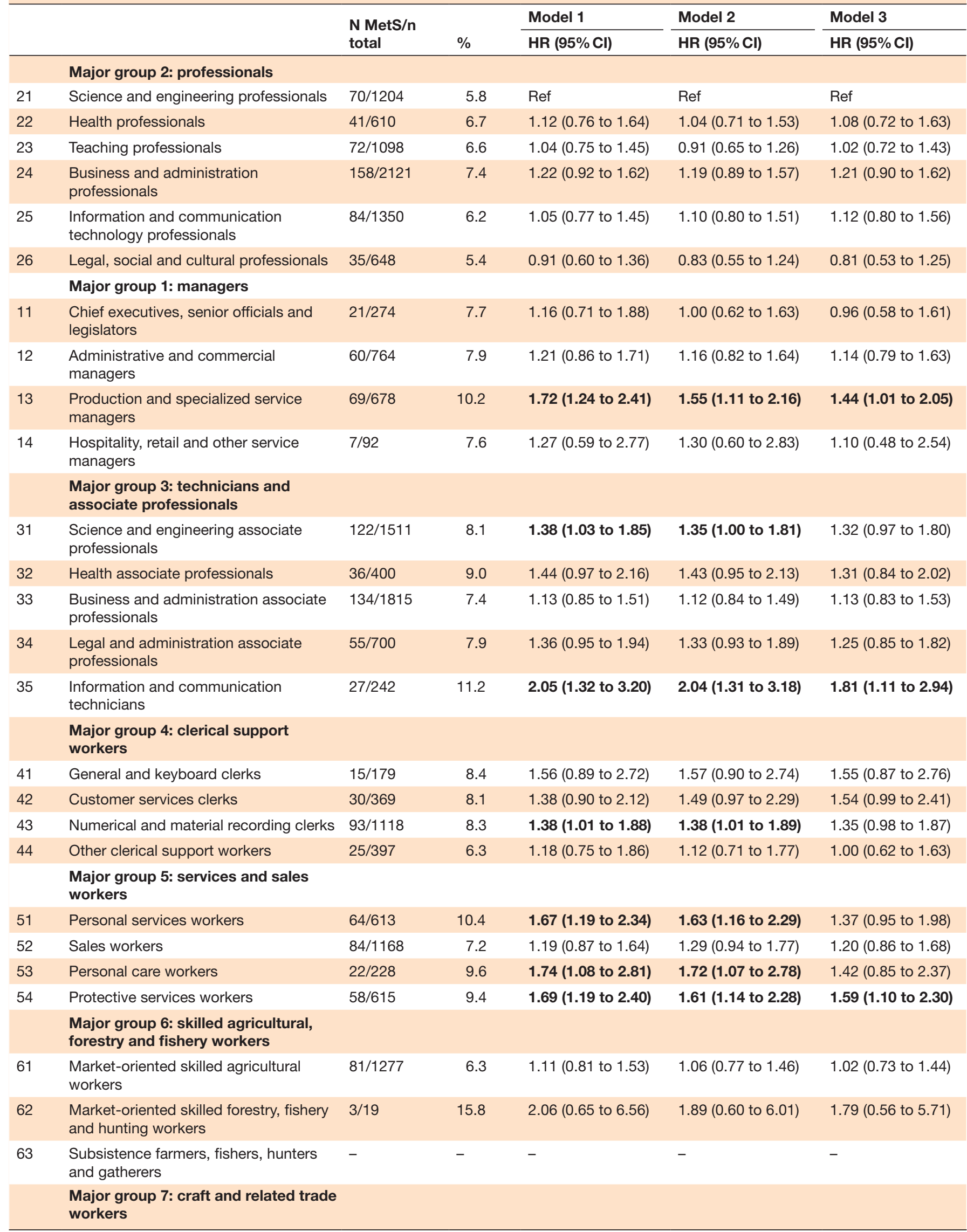




\begin{tabular}{|c|c|c|c|c|c|c|}
\hline & & \multirow{2}{*}{$\begin{array}{l}\text { N MetS/n } \\
\text { total }\end{array}$} & \multirow[b]{2}{*}{$\%$} & \multirow{2}{*}{$\begin{array}{l}\text { Model } 1 \\
\text { HR }(95 \% \mathrm{Cl})\end{array}$} & \multirow{2}{*}{$\begin{array}{l}\text { Model } 2 \\
\text { HR }(95 \% \mathrm{Cl})\end{array}$} & \multirow{2}{*}{$\begin{array}{l}\text { Model } 3 \\
\text { HR }(95 \% \mathrm{Cl})\end{array}$} \\
\hline & & & & & & \\
\hline 71 & $\begin{array}{l}\text { Building and related trade workers } \\
\text { (excluding electricians) }\end{array}$ & $141 / 1642$ & 8.6 & 1.37 (1.03 to 1.83$)$ & 1.37 (1.03 to 1.83$)$ & $1.27(0.93$ to 1.72$)$ \\
\hline 72 & $\begin{array}{l}\text { Metal, machinery and related trade } \\
\text { workers }\end{array}$ & $94 / 1255$ & 7.5 & 1.15 (0.84 to 1.57$)$ & $1.17(0.86$ to 1.60$)$ & $1.08(0.77$ to 1.49$)$ \\
\hline 73 & Handicraft and printing workers & $14 / 160$ & 8.8 & 1.25 (0.70 to 2.22$)$ & 1.24 (0.70 to 2.19$)$ & 1.15 (0.63 to 2.09$)$ \\
\hline 74 & Electrical and electronics trade workers & $49 / 464$ & 10.6 & 1.72 (1.19 to 2.48$)$ & $1.73(1.20$ to 2.50$)$ & 1.83 (1.25 to 2.68$)$ \\
\hline \multirow[t]{2}{*}{75} & $\begin{array}{l}\text { Food processing, woodworking, } \\
\text { garment and other craft and related } \\
\text { trade workers }\end{array}$ & $37 / 478$ & 7.7 & $1.32(0.89$ to 1.97$)$ & 1.31 (0.88 to 1.95$)$ & $1.09(0.72$ to 1.67$)$ \\
\hline & $\begin{array}{l}\text { Major group 8: plant and machine } \\
\text { operators and assemblers }\end{array}$ & & & & & \\
\hline 81 & Stationary plant and machine operators & $31 / 326$ & 9.5 & 1.88 (1.23 to 2.86$)$ & $1.83(1.20$ to 2.80$)$ & $1.94(1.26$ to 3.00$)$ \\
\hline 82 & Assemblers & $6 / 76$ & 7.9 & 1.25 (0.54 to 2.89$)$ & 1.38 (0.60 to 3.18$)$ & $1.32(0.57$ to 3.06$)$ \\
\hline \multirow[t]{2}{*}{83} & Drivers and mobile plant operators & $102 / 1065$ & 9.6 & 1.69 (1.24 to 2.29$)$ & $1.63(1.20$ to 2.21$)$ & 1.44 (1.04 to 1.98$)$ \\
\hline & $\begin{array}{l}\text { Major group 9: elementary } \\
\text { occupations }\end{array}$ & & & & & \\
\hline 91 & Cleaners and helpers & $19 / 211$ & 9.0 & 1.74 (1.05 to 2.88$)$ & 1.79 (1.08 to 2.97$)$ & $1.47(0.86$ to 2.52$)$ \\
\hline 92 & Agricultural, forestry and fishery laborers & $5 / 50$ & 10.0 & 2.81 (1.13 to 6.97$)$ & 2.80 (1.13 to 6.93$)$ & $2.18(0.79$ to 6.01$)$ \\
\hline 93 & $\begin{array}{l}\text { Laborers in mining, construction, } \\
\text { manufacturing and transport }\end{array}$ & $50 / 582$ & 8.6 & 1.45 (1.01 to 2.08$)$ & $1.63(1.13$ to 2.34$)$ & 1.63 (1.12 to 2.38$)$ \\
\hline 94 & Food preparation assistants & $1 / 47$ & 2.1 & 0.39 (0.05 to 2.83$)$ & 0.49 (0.07 to 3.50$)$ & $0.48(0.07$ to 3.50$)$ \\
\hline 95 & $\begin{array}{l}\text { Street and related sales and services } \\
\text { workers }\end{array}$ & - & - & - & - & - \\
\hline 96 & $\begin{array}{l}\text { Refuse workers and other elementary } \\
\text { workers }\end{array}$ & $5 / 101$ & 5.0 & 0.82 (0.33 to 2.04$)$ & 0.84 (0.34 to 2.08$)$ & $0.92(0.37$ to 2.28$)$ \\
\hline
\end{tabular}

Model 1 is unadjusted; model 2 is adjusted for age; model 3 is adjusted for age, smoking, physical activity, diet, and alcohol consumption. Statistical significant associations are shown in bold.

MetS, metabolic syndrome.

highest HRs for MetS. Only one occupational group (ie, 'drivers and mobile plant operators') was associated with an increased risk for MetS in both men and women; all others were sex specific.

\section{CONCLUSIONS}

In a longitudinal study among 75000 Dutch workers from 40 submajor occupational groups, MetS prevalence and incidence were associated with occupational group membership. Age and health behaviors do not account for the increased risk in all occupational groups. The occupational groups that matter differ for men and women except the occupational group 'drivers and mobile plant operators'. In addition, occupational groups associated with MetS vary between prevalence and incidence.

Findings from the current cross-sectional and longitudinal analyses are in line with findings from previous cross-sectional studies on the association between occupational group membership and MetS ${ }^{7-10}$ or components of MetS. ${ }^{11-16}$ Previous studies found that MetS prevalence rates were high for male 'machine installers, operators, and assemblers' $(15.1 \%)$ and for female 'skilled workers in agricultural and fishing industries' $(8.9 \%),{ }^{7}$ and for non-sex specified, 'food preparation and service occupations' $(31.1 \%) .{ }^{10}$ Prevalence rates in the current study confirm these findings as male 'drivers and mobile plant operators' (25.7\%) and female 'assemblers' $(21.7 \%)$ had the highest baseline rates of MetS. Although there are differences in the magnitude of the prevalence between these studies, similar occupational groups showed the highest MetS rates. The incidence rates in the current study showed similar results. Male 'marketoriented skilled forestry, fishery and hunting workers' $(15.8 \%)$ and female 'drivers and mobile plant operators' had the highest incidence rates of MetS. Female 'food preparation assistants' (19.6\%) also had high incident rates of MetS, confirming findings from the USA. ${ }^{10}$

This is the first longitudinal study to identify that occupational group membership may play a role in the development of MetS. Longitudinal analyses showed that even after adjustment for age and health behaviors, males in seven occupational groups and females in five occupational groups had an increased risk to develop MetS. These findings indicate that occupational group matters for both men and women in the development of MetS, and suggest that differences in MetS prevalence across occupations in previous cross-sectional studies are not merely a reflection of selection of metabolically 
Table 3 The incidence of metabolic syndrome among women, and its association with submajor occupational groups

\begin{tabular}{|c|c|c|c|c|c|c|}
\hline & & \multirow{2}{*}{$\begin{array}{l}\text { N MetS/n } \\
\text { total }\end{array}$} & \multirow[b]{2}{*}{$\%$} & \multirow{2}{*}{$\begin{array}{l}\text { Model } 1 \\
\text { HR }(95 \% \mathrm{Cl})\end{array}$} & \multirow{2}{*}{$\begin{array}{l}\text { Model } 2 \\
\text { HR }(95 \% \mathrm{Cl})\end{array}$} & \multirow{2}{*}{$\begin{array}{l}\text { Model } 3 \\
\text { HR }(95 \% \mathrm{Cl})\end{array}$} \\
\hline & & & & & & \\
\hline & Major group 2: professionals & & & & & \\
\hline 21 & Science and engineering professionals & $22 / 273$ & 8.1 & Ref & Ref & Ref \\
\hline 22 & Health professionals & $320 / 2904$ & 11.0 & 1.35 (0.87 to 2.07$)$ & $1.39(0.90$ to 2.14$)$ & 1.29 (0.83 to 2.00$)$ \\
\hline 23 & Teaching professionals & $384 / 3050$ & 12.6 & 1.54 (1.00 to 2.36$)$ & 1.61 (1.05 to 2.48$)$ & $1.45(0.93$ to 2.25$)$ \\
\hline 24 & Business and administration professionals & $187 / 1808$ & 10.3 & $1.27(0.81$ to 1.97$)$ & $1.30(0.84$ to 2.03$)$ & $1.19(0.46$ to 1.88$)$ \\
\hline 25 & $\begin{array}{l}\text { Information and communication technology } \\
\text { professionals }\end{array}$ & $27 / 235$ & 11.5 & 1.38 (0.79 to 2.43$)$ & $1.42(0.81$ to 2.50$)$ & 1.30 (0.73 to 2.32$)$ \\
\hline \multirow[t]{2}{*}{26} & Legal, social and cultural professionals & $148 / 1282$ & 11.5 & 1.48 (0.95 to 2.32$)$ & $1.52(0.97$ to 2.37$)$ & $1.40(0.88$ to 2.21$)$ \\
\hline & Major group 1: managers & & & & & \\
\hline 11 & $\begin{array}{l}\text { Chief executives, senior officials and } \\
\text { legislators }\end{array}$ & $11 / 124$ & 8.9 & 0.98 (0.48 to 2.03$)$ & $1.07(0.52$ to 2.20$)$ & $1.02(0.49$ to 2.12$)$ \\
\hline 12 & Administrative and commercial managers & $44 / 384$ & 11.5 & $1.36(0.81$ to 2.27$)$ & $1.45(0.87$ to 2.41$)$ & $1.20(0.71$ to 2.04$)$ \\
\hline 13 & Production and specialized service managers & $29 / 308$ & 9.4 & $1.02(0.58$ to 1.77$)$ & $1.10(0.63$ to 1.92$)$ & 1.04 (0.59 to 1.86$)$ \\
\hline \multirow[t]{2}{*}{14} & Hospitality, retail and other service managers & $15 / 88$ & 17.0 & 1.79 (0.93 to 3.45$)$ & 1.91 (0.99 to 3.68$)$ & 1.35 (0.68 to 2.70$)$ \\
\hline & $\begin{array}{l}\text { Major group 3: technicians and associate } \\
\text { professionals }\end{array}$ & & & & & \\
\hline 31 & $\begin{array}{l}\text { Science and engineering associate } \\
\text { professionals }\end{array}$ & $30 / 245$ & 12.2 & 1.45 (0.84 to 2.51$)$ & $1.50(0.86$ to 2.60$)$ & $1.23(0.70$ to 2.15$)$ \\
\hline 32 & Health associate professionals & $317 / 2569$ & 12.3 & 1.49 (0.97 to 2.30$)$ & 1.53 (0.99 to 2.36$)$ & $1.32(0.85$ to 2.05$)$ \\
\hline 33 & $\begin{array}{l}\text { Business and administration associate } \\
\text { professionals }\end{array}$ & $360 / 2682$ & 13.4 & 1.65 (1.08 to 2.55$)$ & 1.71 (1.11 to 2.63$)$ & 1.41 (0.91 to 2.19$)$ \\
\hline 34 & $\begin{array}{l}\text { Legal and administration associate } \\
\text { professionals }\end{array}$ & $343 / 2561$ & 13.4 & 1.67 (1.08 to 2.57$)$ & 1.71 (1.11 to 2.64$)$ & $1.43(0.92$ to 2.22$)$ \\
\hline \multirow[t]{2}{*}{35} & Information and communication technicians & $11 / 93$ & 11.8 & 1.76 (0.85 to 3.62$)$ & $1.85(0.90$ to 3.82$)$ & $1.36(0.64$ to 2.89$)$ \\
\hline & Major group 4: clerical support workers & & & & & \\
\hline 41 & General and keyboard clerks & $255 / 1817$ & 14.0 & $1.74(1.13$ to 2.69$)$ & 1.85 (1.19 to 2.85$)$ & $1.50(0.96$ to 2.35$)$ \\
\hline 42 & Customer services clerks & $206 / 1330$ & 15.5 & $1.92(1.24$ to 2.99$)$ & 2.02 (1.30 to 3.13$)$ & $1.66(1.06$ to 2.61$)$ \\
\hline 43 & Numerical and material recording clerks & $186 / 1447$ & 12.9 & 1.59 (1.02 to 2.48$)$ & 1.69 (1.09 to 2.63$)$ & $1.41(0.89$ to 2.22$)$ \\
\hline \multirow[t]{2}{*}{44} & Other clerical support workers & $124 / 910$ & 13.6 & $1.80(1.14$ to 2.83$)$ & 1.90 (1.21 to 2.99$)$ & $1.53(0.96$ to 2.45$)$ \\
\hline & Major group 5: services and sales workers & & & & & \\
\hline 51 & Personal services workers & $276 / 2067$ & 13.4 & 1.69 (1.09 to 2.61$)$ & 1.70 (1.10 to 2.63$)$ & $1.38(0.89$ to 2.16$)$ \\
\hline 52 & Sales workers & $450 / 3269$ & 13.8 & $1.72(1.12$ to 2.64$)$ & 1.71 (1.11 to 2.62$)$ & $1.35(0.87$ to 2.10$)$ \\
\hline 53 & Personal care workers & $727 / 4970$ & 14.6 & $1.82(1.19$ to 2.78$)$ & 1.95 (1.28 to 2.99$)$ & 1.63 (1.05 to 2.52$)$ \\
\hline \multirow[t]{2}{*}{54} & Protective services workers & $32 / 286$ & 11.2 & 1.41 (0.82 to 2.43$)$ & $1.44(0.84$ to 2.48$)$ & 1.25 (0.71 to 2.19$)$ \\
\hline & $\begin{array}{l}\text { Major group 6: skilled agricultural, forestry } \\
\text { and fishery workers }\end{array}$ & & & & & \\
\hline 61 & Market-oriented skilled agricultural workers & $24 / 337$ & 7.1 & $1.06(0.59$ to 1.89$)$ & $1.16(0.65$ to 2.07$)$ & $1.06(0.58$ to 1.91$)$ \\
\hline 62 & $\begin{array}{l}\text { Market-oriented skilled forestry, fishery and } \\
\text { hunting workers }\end{array}$ & - & - & - & - & - \\
\hline \multirow[t]{2}{*}{63} & $\begin{array}{l}\text { Subsistence farmers, fishers, hunters and } \\
\text { gatherers }\end{array}$ & - & - & - & - & - \\
\hline & $\begin{array}{l}\text { Major group 7: craft and related trade } \\
\text { workers }\end{array}$ & & & & & \\
\hline 71 & $\begin{array}{l}\text { Building and related trade workers (excluding } \\
\text { electricians) }\end{array}$ & $6 / 64$ & 9.4 & $1.11(0.45$ to 2.74$)$ & $1.20(0.49$ to 2.96$)$ & $1.12(0.42$ to 2.98$)$ \\
\hline 72 & Metal, machinery and related trade workers & $4 / 42$ & 9.5 & 1.08 (0.37 to 3.12$)$ & $1.14(0.39$ to 3.31$)$ & $0.93(0.28$ to 3.11$)$ \\
\hline 73 & Handicraft and printing workers & $7 / 73$ & 9.6 & 1.07 (0.46 to 2.52$)$ & $1.11(0.47$ to 2.60$)$ & $1.23(0.52$ to 2.90$)$ \\
\hline 74 & Electrical and electronics trade workers & - & - & - & - & - \\
\hline 75 & $\begin{array}{l}\text { Food processing, woodworking, garment and } \\
\text { other craft and related trade workers }\end{array}$ & $44 / 297$ & 14.8 & $1.97(1.18$ to 3.29$)$ & $2.04(1.22$ to 3.41$)$ & 1.69 (1.00 to 2.86$)$ \\
\hline
\end{tabular}




\begin{tabular}{|c|c|c|c|c|c|c|}
\hline & & \multirow{2}{*}{$\begin{array}{l}\text { N MetS/n } \\
\text { total }\end{array}$} & \multirow[b]{2}{*}{$\%$} & \multirow{2}{*}{$\begin{array}{l}\text { Model } 1 \\
\text { HR }(95 \% \mathrm{Cl})\end{array}$} & \multirow{2}{*}{$\begin{array}{l}\text { Model } 2 \\
\text { HR }(95 \% \mathrm{Cl})\end{array}$} & \multirow{2}{*}{$\begin{array}{l}\text { Model } 3 \\
\text { HR }(95 \% \mathrm{Cl})\end{array}$} \\
\hline & & & & & & \\
\hline & $\begin{array}{l}\text { Major group 8: plant and machine operators } \\
\text { and assemblers }\end{array}$ & & & & & \\
\hline 81 & Stationary plant and machine operators & $10 / 93$ & 10.8 & 1.23 (0.58 to 2.60$)$ & 1.33 (0.63 to 2.80$)$ & 1.05 (0.49 to 2.23$)$ \\
\hline 82 & Assemblers & $7 / 36$ & 19.4 & 3.18 (1.36 to 7.44$)$ & 3.26 (1.39 to 7.64$)$ & 1.95 (0.79 to 4.83$)$ \\
\hline \multirow[t]{2}{*}{83} & Drivers and mobile plant operators & $36 / 172$ & 20.9 & 2.36 (1.39 to 4.01$)$ & 2.57 (1.51 to 4.37$)$ & 1.77 (1.01 to 3.08$)$ \\
\hline & Major group 9: elementary occupations & & & & & \\
\hline 91 & Cleaners and helpers & $300 / 1859$ & 16.1 & 2.07 (1.34 to 3.19$)$ & $2.27(1.47$ to 3.51$)$ & 1.73 (1.11 to 2.70$)$ \\
\hline 92 & Agricultural, forestry and fishery laborers & $8 / 59$ & 13.6 & $2.00(0.89$ to 4.50$)$ & 1.99 (0.89 to 4.48$)$ & $1.98(0.84$ to 4.66$)$ \\
\hline 93 & $\begin{array}{l}\text { Laborers in mining, construction, } \\
\text { manufacturing and transport }\end{array}$ & $35 / 265$ & 13.2 & 1.65 (0.97 to 2.81$)$ & $1.62(0.95$ to 2.77$)$ & 1.18 (0.68 to 2.05$)$ \\
\hline 94 & Food preparation assistants & $28 / 143$ & 19.6 & 2.45 (1.40 to 4.29$)$ & 2.39 (1.37 to 4.18$)$ & 1.80 (1.01 to 3.22$)$ \\
\hline 95 & Street and related sales and services workers & - & - & - & - & - \\
\hline 96 & Refuse workers and other elementary workers & $10 / 82$ & 12.2 & $1.64(0.77$ to 3.45$)$ & 1.65 (0.78 to 3.49$)$ & $1.29(0.61$ to 2.75$)$ \\
\hline
\end{tabular}

Model 1 is unadjusted; model 2 is adjusted for age; model 3 is adjusted for age, smoking, physical activity, diet, and alcohol consumption. Statistical significant associations are shown in bold. MetS, metabolic syndrome.

unhealthy workers into specific occupations. However, caution is warranted when interpreting the results since occupation is an aggregate exposure measure and does not show which individuals in specific jobs have, or developed, MetS. The development of MetS likely results from a combination of individual and contextual factors consisting of work-related physical activity, ${ }^{29}$ the psychosocial work environment, ${ }^{21}$ the social and physical work environment, ${ }^{30}$ health behaviors, ${ }^{17}$ and pre-existing biological factors. ${ }^{31}$ Disentangling the contribution of these factors in future studies may aid the development of measures to prevent MetS.

Notable differences between men and women in MetS prevalence and incidence rates were observed. Regarding baseline prevalence, only three occupational groups were associated with an increased odds for MetS in both men and women while there were three male-specific and nine female-specific occupational groups associated with an increased odds for MetS. Regarding the incidence, there was only one occupational group that was associated with an increased risk for MetS in both men and women while there were six male-specific and four female-specific occupational groups with an increased risk for MetS. In line with a previous study, ${ }^{7}$ we found an increased risk for MetS among males in the high-end occupational groups 'production and specialized services managers' and 'information and communication technicians', while we found no increased risk for women in similar high-end occupational groups. A Korean study also found similar results when examining different employment sectors. ${ }^{32}$ While the prevalence of MetS was highest among higher $(29.3 \%)$ and lower $(31.1 \%)$ skilled white-collar workers in men, and lowest in unskilled blue-collar workers (21.9\%), the opposite was found in women. Female unskilled bluecollar $(24.0 \%)$ and green-collar $(24.2 \%)$ workers had the highest prevalence of MetS, while female higher skilled white-collar $(16.6 \%)$ workers had the lowest prevalence. ${ }^{32}$ The sex differences in this and previous studies may be related to the make-up of the workforce, that is, more men or women in certain professions. Nevertheless, these findings suggest that preventive measures should differentially target men and women based on occupational group.

This study has some notable strengths. First, all components of MetS were objectively measured by trained research staff at one of the Lifelines research centers. In addition, trained research nurses recorded baseline medication use according to the ATC codes. ${ }^{26}$ The risk for information bias regarding MetS diagnosis was thereby limited. Second, occupational group membership was coded by Statistics Netherlands and underwent rigorous quality control by Statistics Netherlands and the study research team, and is deemed valid on the submajor group level. ${ }^{24}$ Third, the analyses were adjusted for age and four major health behavior factors that may confound the relationship between occupational group membership and MetS. This provides insight into the role of the occupational group separate from health behaviors that might influence MetS. Fifth, Lifelines is representative of the general population in the northern part of the Netherlands. ${ }^{33}$

This study also has some limitations. First, despite rigorous quality control by Statistics Netherlands on the automatic occupational coding, we cannot rule out some degree of misclassification. Our investigation of the automatic coding showed that at least $81 \%$ of participants are coded correctly on the submajor occupational level (twodigit level). In addition, we found no evidence for differential misclassification when we examined patterns of misclassification. Second, a substantial proportion of the 
participants at baseline did not yet complete the second follow-up measurement or were lost to follow-up, which may have induced some selection bias. Attrition analyses showed that participants without follow-up data differed significantly at baseline from participants with follow-up data regarding sociodemographic, health behavior and health-related characteristics. However, these differences were small and did not seem clinically relevant, indicating that the risk for selection bias is low. Third, MetS diagnosis during follow-up was based on physical measurements without considering medication use, as information on changes in medication was not available during follow-up. This may have resulted in missing incident MetS cases during follow-up, and thereby in an underestimation of MetS incidence. Finally, despite adjusting the analyses for four major health behavior factors, some residual confounding may be present due to the rather crude measurement of alcohol consumption and diet. Other dietary factors than fruit and vegetable intake may affect the development of MetS. In addition, unmeasured confounding might have occurred as, for example, our analyses were not adjusted for psychosocial working conditions. ${ }^{21}$

The study findings may have important implications for policy and practice. Non-sex-specific preventive measures and increased awareness regarding MetS are especially necessary among 'customer services clerks', 'stationary plant and machine operators', and 'drivers and mobile plant operators' while sex-specific approaches might be needed for other occupational groups (eg, female 'cleaners and helpers'). Given the fact that many countries are increasing their retirement age, and MetS risk increases with age, MetS may become a serious problem in workers' late work-life. ${ }^{34}$ Chronic conditions like cardiovascular disease and T2DM are likely to develop as a result from MetS, ${ }^{217}$ and are major risk factors for early work exit. ${ }^{35}$ Lifestyle and medication counseling programs may be beneficial for workers with MetS or with an increased risk for MetS as programs to reduce T2DM and coronary heart disease risk in individuals with an increased risk for these conditions have shown to be effective. ${ }^{36} 37$ Although implementation of health behavior interventions at the occupational level or worksite may pose challenges, ${ }^{38}$ they may be effective regarding body mass index,$^{39}$ sedentary behavior, ${ }^{40}$ and eating behavior. ${ }^{41}$

Study findings also have important implications for researchers. To further disentangle selection and causation mechanisms, future studies need to examine the relationship between occupational group membership and MetS in a cohort of young adults entering the workforce. Such an approach may help disentangle selection and causation mechanisms since young adults entering the workforce have not been exposed to the circumstances related to their occupational group. ${ }^{42}$ Second, as people may change jobs and consequently occupational groups over time, their risk exposure level for developing MetS may change as well. Therefore, studies using a life course perspective, incorporating work history and job duration in analyses on the association between occupational group membership and MetS, are necessary. Third, researchers should further investigate how the workplace can be optimized as a setting for health promotion and prevention of cardiometabolic conditions like MetS.

To conclude, this study suggests that the occupational group matters for the prevalence and incidence of MetS independent of age and health behaviors, although future studies that consider other factors not included in the present analysis need to confirm our findings. The striking sex differences in the occupational distribution of MetS indicate that preventive measures should, with some exceptions, target male and female employees separately.

\section{Author affiliations}

${ }^{1}$ Department of Health Sciences, Community and Occupational Medicine, University of Groningen, University Medical Center Groningen, Groningen, The Netherlands ${ }^{2}$ Department of Epidemiology, University of Arkansas for Medical Sciences Fay W Boozman College of Public Health, Little Rock, Arkansas, USA

${ }^{3}$ Lifelines Cohort and Biobank Study, Roden, The Netherlands

Acknowledgements The authors acknowledge the services of the Lifelines Cohort Study, the contributing research centers delivering data to Lifelines, and all the study participants.

Contributors All authors conceived the study. SKRvZ analyzed the data and wrote the initial draft. All authors were involved in the interpretation of the results and made substantial contributions to the final draft. All authors approved its submission. UB is the guarantor of this work and, as such, had full access to all the data in the study and takes responsibility for the integrity of the data and the accuracy of the data analysis.

Funding The Lifelines Cohort Study is supported by the Netherlands Organization of Scientific Research NWO (grant 175.010.2007.006), the Ministry of Economic Affairs, the Ministry of Education, Culture and Science, the Ministry for Health, Welfare and Sports, the Northern Netherlands Collaboration of Provinces (SNN), the Province of Groningen, University Medical Center Groningen, the University of Groningen, Dutch Kidney Foundation and Dutch Diabetes Research Foundation.

Competing interests None declared.

Patient consent for publication Not required.

Ethics approval Lifelines was conducted according to the guidelines in the Declaration of Helsinki and the Medical Ethics Committee of the University Medical Center Groningen approved all the procedures involving human subjects (ethics number: 2007/152). Written informed consent was obtained from all participants.

Provenance and peer review Not commissioned; externally peer reviewed.

Data availability statement Data are available in a public, open access repository. Lifelines is a facility that is open for all researchers. Information on application and data access procedure is summarized on www.lifelines.nl.

Open access This is an open access article distributed in accordance with the Creative Commons Attribution 4.0 Unported (CC BY 4.0) license, which permits others to copy, redistribute, remix, transform and build upon this work for any purpose, provided the original work is properly cited, a link to the licence is given, and indication of whether changes were made. See: https://creativecommons.org/ licenses/by/4.0/.

\section{ORCID iD}

Sander K R van Zon http://orcid.org/0000-0002-1956-1225

\section{REFERENCES}

1 Alberti KGMM, Eckel RH, Grundy SM, et al. Harmonizing the metabolic syndrome: a joint interim statement of the International diabetes Federation Task force on epidemiology and prevention; National heart, lung, and blood Institute; American heart association; world heart Federation; international atherosclerosis Society; 
and international association for the study of obesity. Circulation 2009;120:1640-5.

2 Mottillo S, Filion KB, Genest J, et al. The metabolic syndrome and cardiovascular risk a systematic review and meta-analysis. J Am Coll Cardiol 2010;56:1113-32.

3 Shin J-A, Lee J-H, Lim S-Y, et al. Metabolic syndrome as a predictor of type 2 diabetes, and its clinical interpretations and usefulness. $J$ Diabetes Investig 2013;4:334-43.

4 Boudreau DM, Malone DC, Raebel MA, et al. Health care utilization and costs by metabolic syndrome risk factors. Metab Syndr Relat Disord 2009;7:305-14.

5 Saklayen MG. The global epidemic of the metabolic syndrome. Curr Hypertens Rep 2018;20:12.

6 Scuteri A, Laurent S, Cucca F, et al. Metabolic syndrome across Europe: different clusters of risk factors. Eur J Prev Cardiol 2015;22:486-91.

7 Sánchez-Chaparro M-A, Calvo-Bonacho E, González-Quintela A, et al. Occupation-related differences in the prevalence of metabolic syndrome. Diabetes Care 2008;31:1884-5.

$8 \mathrm{Nam}$ JY, Kim J, Cho KH, et al. Associations of sitting time and occupation with metabolic syndrome in South Korean adults: a cross-sectional study. BMC Public Health 2016;16:943.

9 Hidaka T, Hayakawa T, Kakamu T, et al. Prevalence of metabolic syndrome and its components among Japanese workers by clustered business category. PLoS One 2016;11:e0153368.

10 Davila EP, Florez H, Fleming LE, et al. Prevalence of the metabolic syndrome among U.S. workers. Diabetes Care 2010;33:2390-5.

11 Caban AJ, Lee DJ, Fleming LE, et al. Obesity in US workers: the National health interview survey, 1986 to 2002. Am J Public Health 2005;95:1614-22.

12 Proper KI, Hildebrandt VH. Overweight and obesity among Dutch workers: differences between occupational groups and sectors. Int Arch Occup Environ Health 2010;83:61-8.

13 Gu JK, Charles LE, Bang KM, et al. Prevalence of obesity by occupation among US workers: the National health interview survey 2004-2011. J Occup Environ Med 2014;56:516-28.

14 Luckhaupt SE, Cohen MA, Li J, et al. Prevalence of obesity among U.S. workers and associations with occupational factors. Am J Prev Med 2014;46:237-48.

15 Davila EP, Kuklina EV, Valderrama AL, et al. Prevalence, management, and control of hypertension among US workers: does occupation matter? J Occup Environ Med 2012;54:1150-6.

16 Landsbergis PA, Diez-Roux AV, Fujishiro K, et al. Job strain, occupational category, systolic blood pressure, and hypertension prevalence: the multi-ethnic study of atherosclerosis. J Occup Environ Med 2015;57:1178-84.

17 Pérez-Martínez P, Mikhailidis DP, Athyros VG, et al. Lifestyle recommendations for the prevention and management of metabolic syndrome: an international panel recommendation. Nutr Rev 2017;75:307-26.

18 Poulsen P, Vaag A, Kyvik K, et al. Genetic versus environmental aetiology of the metabolic syndrome among male and female twins. Diabetologia 2001;44:537-43.

19 Eckel RH, Grundy SM, Zimmet PZ. The metabolic syndrome. Lancet 2005;365:1415-28.

20 Björntorp P. Heart and soul: stress and the metabolic syndrome. Scand Cardiovasc J 2001;35:172-7.

21 Watanabe K, Sakuraya A, Kawakami N, et al. Work-Related psychosocial factors and metabolic syndrome onset among workers: a systematic review and meta-analysis. Obes Rev 2018;19:1557-68.

22 Scholtens S, Smidt N, Swertz MA, et al. Cohort profile: lifelines, a three-generation cohort study and Biobank. Int J Epidemiol 2015;44:1172-80.

23 Janssen B, Dirven H. Sociaaleconomische trends. Werkloosheid: twee afbakeningen. The Hague: Statistics Netherlands, 2015.
24 International Labour Office. International Standard Classification of Occupations. Structure, group definitions and correspondence tables. Geneva: International Labour Office, 2012.

25 International Labour Organization. ISCO-08 Part 1: introductory and methodological notes. Available: http://www.ilo.org/public/ english/bureau/stat/isco/isco08/index.htm [Accessed 12 Feb 2020].

26 WHO Collaborating Centre for Drug Statistics Methodology. ATC/ DDD index, 2020. Available: http://www.whocc.no/atc_ddd index/ [Accessed Last accessed 12 February 2020].

27 van Zon SKR, Reijneveld SA, van der Most PJ, et al. The interaction of genetic predisposition and socioeconomic position with type 2 diabetes mellitus: cross-sectional and longitudinal analyses from the lifelines cohort and Biobank study. Psychosom Med 2018;80:252-62.

28 Gezondheidsraad (Health Council of the Netherlands). Richtlijnen goede voeding 2015 (guidelines healthy nutrition 2015). The Hague: Gezondheidsraad 2015; publicatienr, 2015. Available: https://www. gezondheidsraad.nl/documenten/adviezen/2015/11/04/richtlijnengoede-voeding-2015

29 Brighenti-Zogg S, Mundwiler J, Schüpbach U, et al. Physical workload and work capacity across occupational groups. PLoS One 2016;11:e0154073.

30 Syamlal G, Mazurek JM, Hendricks SA, et al. Cigarette smoking trends among U.S. working adult by industry and occupation: findings from the 2004-2012 National health interview survey. Nicotine Tob Res 2015;17:599-606.

31 Fall T, Ingelsson E. Genome-Wide association studies of obesity and metabolic syndrome. Mol Cell Endocrinol 2014;382:740-57.

32 Lee W, Yeom H, Yoon J-H, et al. Metabolic outcomes of workers according to the International standard classification of occupations in Korea. Am J Ind Med 2016;59:685-94.

33 Klijs B, Scholtens S, Mandemakers JJ, et al. Representativeness of the lifelines cohort study. PLoS One 2015;10:e0137203.

34 Harper S. Economic and social implications of aging societies. Science 2014;346:587-91.

35 Kouwenhoven-Pasmooij TA, Burdorf A, Roos-Hesselink JW, et al. Cardiovascular disease, diabetes and early exit from paid employment in Europe; the impact of work-related factors. Int $J$ Cardiol 2016;215:332-7.

$36 \mathrm{Hu}$ G, Lindström J, Valle TT, et al. Physical activity, body mass index, and risk of type 2 diabetes in patients with normal or impaired glucose regulation. Arch Intern Med 2004;164:892-6.

37 Keyserling TC, Sheridan SL, Draeger LB, et al. A comparison of live counseling with a web-based lifestyle and medication intervention to reduce coronary heart disease risk: a randomized clinical trial. JAMA Intern Med 2014;174:1144-57.

38 Robroek SJ, van Lenthe FJ, van Empelen P, et al. Determinants of participation in worksite health promotion programmes: a systematic review. Int J Behav Nutr Phys Act 2009;6:26.

39 Anderson LM, Quinn TA, Glanz K, et al. The effectiveness of worksite nutrition and physical activity interventions for controlling employee overweight and obesity: a systematic review. Am J Prev Med 2009;37:340-57.

40 Commissaris DA, Huysmans MA, Mathiassen SE, et al. Interventions to reduce sedentary behavior and increase physical activity during productive work: a systematic review. Scand J Work Environ Health 2016:42:181-91.

41 Allan J, Querstret D, Banas K, et al. Environmental interventions for altering eating behaviours of employees in the workplace: a systematic review. Obes Rev 2017;18:214-26.

42 Amick BC, McLeod CB, Bültmann U. Labor markets and health: an integrated life course perspective. Scand J Work Environ Health 2016;42:346-53. 